Session 2480

\title{
An Evaluation of Using a Study Team Seminar Course to Increase Retention of Students in Introductory Math and Physics Courses
}

\author{
Joan V. Dannenhoffer, Nicole Loock \\ State University of New York, Morrisville
}

\begin{abstract}
One of the unseen costs in college education is the high freshman year dropout rate experienced in most two- and four-year colleges. Although there has been a significant body of literature discussing retention programs, the overall retention rate has not changed very much over the last century. Recently, several universities have expended considerable resources to ameliorate freshman-year attrition rates. A new approach, which is student-centered and requires fewer resources than many retention programs, has been pioneered at SUNY Morrisville. This approach, described herein, is a Study Team Seminar Course (STSC) based on the concept of teaching students how to form effective study teams with the support of a facilitator. The main goal of the program is to foster student connections that are necessary for retention, while the students build skills that will improve their chance of academic success. The program, which was piloted in the Fall of 2002 for gatekeeper courses in mathematics and physics, was tuned and reoffered in the Spring of 2003. Improved grades, increased class-participation, and improved group development skills and study skills, as reported by surveys of students, faculty, and staff, are the preliminary results of the program. Along with the detailed STSC description, a review of the current retention research and the educational philosophies and models used to design the course is included. Based upon the qualitative results from the pilot and first full-scale offering, improvements that will be made in the future are described.
\end{abstract}

\section{Background}

Freshman year dropout rates over the period from 1983 - 2001 at two-year and four-year public and private institutions have ranged anywhere from $26 \%$ to $46.9 \%$ [1]. Despite much effort, 
these rates have remained stable over this time period. The highest dropout rates occurred at twoyear public institutions in more recent years, with little improvement. These rates are much higher than we would like to see, given the cost of student attrition.

Research on college retention dates back to Johnson [2] in 1926. The research has looked at both sociological and psychological factors that effect student retention. Current researchers, (Tinto, Seidman, Upcraft, Braxton, etc.) agree that the single best predictor of student success, after controlling for student background characteristics (such as ability and academic preparation), is a concept the National Survey of Student Engagement calls "student engagement" [3].

Student engagement is defined in two parts. The first part is "the amount of time and effort students put into their studies and other educationally purposeful activities". The second part is "how the institution deploys its resource... to induce students to participate in activities that lead to the experiences and outcomes that constitute student success (persistence, satisfaction, learning and graduation)".

The "educationally purposeful" activities suggested above are activities that help the student become academically and socially integrated into the academic and social systems of the college. The integration of these experiences and their effect on retention has been researched extensively. Three well known texts that address these educationally purposeful activities, student success, and student retention are Leaving College [4], The Freshman Year Experience [5], and Reworking the Student Departure Puzzle [2]. The philosophies and strategies developed in these texts have been used in the design of the STSC.

Leaving College is the work of Vincent Tinto. His research resulted in a retention model that has been used extensively over the past twenty-five years and remains the dominant model today. Tinto postulates an interactional theory of college student departure that describes the interactions between pre-entry attributes, the college institutional experiences, and success or departure decisions. In Tinto's model, the student's individual pre-entry attributes (such as family background, skill and ability, and prior schooling) are translated into forming individual goals about education and commitment to successful completion of one's college education. These individual goals and commitments interact over time with institutional experiences. This includes academic and social systems, both formal and informal, such as academic performance, faculty/staff interactions, extra curricular activities, and peer group interactions. The extent to which the individual becomes academically and socially integrated into the academic and social systems effects one's departure decisions.

In a recent interview, Tinto identified "the lack of personal connection with others as one of the most significant predictors of leaving" [6]. A student's ability to make personal contacts is central to his model. The model also provides a systems-analysis approach that can be used to analyze the impact of programs on student retention and how retention programs will interact with other programs at an institution. For example, Alan Seidman has used Tinto's model as the framework of his retention formula [1]. The formula includes early identification of at-risk students followed by early, intensive, and continuous intervention. The formula is the basis for designing a successful intervention program that will "be powerful enough to effect change" in the college 
environment. This is significant because the assumption that the deployment of resources needs to affect powerful change is implicit in today's economic conditions.

The second text, "The Freshman Year Experience: Helping Students Survive and Succeed in College", is a compilation of works that came out of the University 101 (freshman seminar program) model developed at the University of South Carolina. The concepts of student engagement and student success are the backbone on which the programs are built. This work presents the development of students and how institutions can foster student success.

Student success is explicitly defined as more than earning a sufficient grade point average to graduate. The definition includes making progress toward fulfilling their educational and personal goals, including developing academic and intellectual competence, establishing and maintaining interpersonal relationships, developing an identity, deciding on a career and lifestyle, maintaining personal health and wellness, and developing an integrated philosophy of life.

Also in this reference, the implementation and effectiveness of freshman seminars as a student engagement tool and how institutions can be responsive to the diverse needs of today's freshmen are presented. Lastly, the importance of building a partnership between faculty and student-affairs professionals, and a model for developing a campus alliance for enhancing freshman success is addressed. Many colleges use this work to model freshman experience programs that are the beginnings of student engagement and ultimately success.

The third text, "Reworking the Student Departure Puzzle", is a critical review of the current research on student retention. The puzzle described in this reference is that the national rate of student attrition from colleges and universities has remained constant for over one-hundred years, despite the efforts made by institutions and the use of Tinto's model. This work does not end with any conclusions, but offers justification and recommendations for future research too numerous to outline in this paper.

As results of the extensive research that has been done, many colleges and universities have developed programs focused on improving retention rates. The programs range from stand-alone programs aimed at specific student populations or problems to programs that are integrated into a comprehensive institutional program.

Three nationally prominent retention programs are at Syracuse University (SU), the University of North Carolina at Charlotte (UNCC), and the University of Iowa. Each of these three programs is different and is included in this paper as representative of the types of student retention programs currently being implemented.

Syracuse University has an integrated and comprehensive approach to improving retention [6]. The approach includes three components: offering a variety of programs that support students, continuing research and assessment into what issues students face in choosing to stay at SU, and coordinating the retention concerns of all SU schools and colleges. As a result, SU's attrition rate for first-year students dropped from 14.6 percent in 1990 to 9.4 percent in 1998. This attrition rate is well below the national average of 32 percent for all colleges. It is also fifty-percent below 
the 18.6 percent rate for "selective" colleges that traditionally have lower attrition rates [1].

The Student Affairs Division Plan at the University of North Carolina at Charlotte aims "to provide services to ameliorate barriers, increase the way students "connect" to the university, and make leadership development one of the hallmarks of the UNCC undergraduate experience" [7]. Supplemental Instruction (SI) is one of the many programs provided under this directive. The results of offering SI showed that students who attended 5 or more SI sessions per semester averaged .5 - 1.0 letter grade higher than those students not regularly attending SI and 97\% of students reported that attending SI sessions helped them prepare for tests.

The University of Iowa has a comprehensive retention program specifically for student-athletes [8]. The basic principal is that "the longer the student-athlete attacks his academic challenges as hard as he attacks his daily practices and competition, the more likely that student-athlete will achieve academic success". The program is under the direction of one full-time staff member "who spearheads a support team, which works directly with students, faculty, and other academic staff members".

The common factor in each of the retention programs described above is the emphasis on student engagement. An alternative approach to achieving student engagement is the Study Team Seminar Course (STSC) described in this paper. This course gives students the resources they need to be successful in gatekeeper courses and the opportunity to make connections with students and faculty. Unlike some of the more complex and resource intensive programs offered at larger institutions, such as Supplemental Instruction, the STSC can be offered at a level that is appropriate for the particular institution.

In the following section, the STSC is described in detail. The educational philosophies and models that form the theoretical underpinning of the course are presented and the connections between these philosophies and models to the design of the STSC are made. A qualitative assessment of the Fall 2002 pilot program is presented, followed by a description of the Spring 2003 implementation. The paper concludes with the lessons learned and recommendations for future offerings of the STSC.

\section{Study Team Seminar Course Description}

A not-for-credit, optional course called Study Team Seminar Course, was developed at SUNY Morrisville. The STSC is one of the stand-alone initiatives used to address the student retention problem at SUNY Morrisville. The course teaches students to form an effective study team with the support of an instructor/facilitator (the Retention Coordinator at SUNY Morrisville).

The STSC was offered in "gatekeeper courses" in mathematics and physics in the Fall 2002 pilot. These gatekeeper courses, typically taken in the freshman year, are necessary prerequisites for more advanced courses in the curriculum. When students don't pass these courses, it either takes them longer than expected to graduate or they tend to leave college, either temporarily or permanently. The STSC encourages students to succeed in the gatekeeper courses and gives 
them confidence in their ability to learn, an important factor in student retention.

The following are the specific and measurable learning objectives for the STSC:

- To teach students how to build and maintain an effective study team.

- To teach, model, and demonstrate leadership principles necessary to build a cohesive and effective study-team.

- To teach students active-learning, study, and test-taking techniques, which they can use to teach their peers the subject they are studying, through peer mentoring.

- To teach students the skills they need to continue to work independently, as a team, after the six-week course (with support from the Retention Coordinator as needed).

- To improve the participants' grades in the gatekeeper classes, especially math and science.

- To periodically and critically assess and evaluate the teaching objectives for the STSC.

- To modify learning objectives based on the assessment.

\section{Course Structure and Content}

The STSC classes meet for two fifty-minute classes each week, for six weeks. Classes are made up of a maximum of four teams of students per class offering. Each team has three to five students who are studying the same subject matter. Each class meeting is a combination of guided instruction (usually mini-lectures), discussion (active learning of the study team skills and the math or physics subject matter), and evaluation (self and team).

The STSC teams progress through four phases of group development (forming, storming, norming, and performing [9]), gradually becoming less dependent on the STSC instructor. Whenever possible, the instructor encourages each team to be as independent as possible and to move along the continuum of development stages as the team's maturity level increases.

Phase One consists of four classes, over a two-week period. The first two weeks of the STSC is very structured with a lot of guidance and support from the instructor (high instructor/leadership involvement - low team autonomy/maturity). Each class begins with guided instruction. During Phase One, the guided instruction is a larger portion of the class time and decreases as the need for guided instruction decreases.

During these first two classes of Phase One, the study teams work on building and forming a team. This is the forming stage of group development. In this stage, group members typically mill about and exchange pleasantries. It is helpful to get the team to work on low-risk tasks and to start thinking about how they want to work together. The forming stage is critical for a team to be able to move on to the next stage of group development, the storming stage. The instructor teaches and role-models several learning objectives to assist with each study team's successful formation.

Two activities are used in the STSC that help the teams form. In the first activity, the team members interview each other and record answers to such questions as: "Why are you taking this 
course?", "What three things help you learn well?", "What three things impede your learning?", and "What do you expect to learn in this class?"

Before the students interview each other, they interview the STSC instructor. This enables the teammates to get to know the instructor and the instructor's expectations of the class without "talking at" or lecturing to them.

For the next activity, each team picks a team name and discusses and agrees upon five study team ground-rules. These two activities help the teams to form efficiently and enable the instructor to ascertain each team's current level of group functioning skills. The instructor uses a checklist and observation notes to track each team's skills over the course of the semester.

During the next two classes of Phase One (week two), the instructor teaches mini-lessons during the first section of each class meeting. The lessons teach team members about two roles, the team manager and the team recorder [9], that enable the study teams to function smoothly when they study.

- Team Manager: this person's responsibility is to help keep the team focused and follow the format that is designed to help keep the team on task.

- Team Recorder: this person's responsibility is to take attendance, write down homework problems and questions each team member has, and write down any additional questions that have not been answered during the study time. Afterwards, everyone can make a copy of the questions and ask their professors in the next class.

In addition, this lesson teaches the team manager and team recorder how to be facilitators and how to help the study team members stay focused and maximize their study time. They also help their study team avoid the following common pitfalls [10]:

- Hero trap - the team relies on one person to answer all of the questions.

- Social trap - the team discusses everything related to life EXCEPT the math or physics subject matter.

- Freeloader trap - under-prepared teammate(s) who rely on others to "give" them the answers.

In the second week, following the mini-lessons, the teams begin to study the math or physics subject matter. The study teams may work on homework problems, review of class notes, conceptual questions, and quiz and test review for approximately twenty to twenty-five minutes.

The instructor quietly observes and evaluates each team's group dynamics, peer-mentoring, and problem-solving abilities using a checklist of skills to records the teams' progress from each class meeting. This enables the instructor to teach according to the student's needs and abilities.

In the last section of each class meeting, during Phase One, the instructor shares his/her evaluations with each team. This is accomplished through a guided discussion during the last ten to fifteen minutes of the class meeting time. Teams learn how to receive constructive feedback 
and to evaluate their own team's performance. The instructor challenges each team to evaluate their performance, beginning with asking them to identify one thing that worked well and one challenge they encountered during the subject-matter study section of the class.

Phase Two usually begins in the third week. At this point, teams will transition from the forming stage to the storming (group conflict) stage of group development. It is a crucial time to teach conflict resolution skills and encourage team members to resolve issues on their own. The instructor also transitions from the role of instructor to that of a facilitator. The teams' maturity levels increase as their skill level improves, thus allowing them to negotiate the conflicts that arise.

In this phase, the first five to ten minutes of class meeting time is used to identify a "group" skill (such as conflict resolution) and study technique that the team would like to work on. Each team practices these skills while they study the math or physics subject matter. The instructor continues to observe and record evaluations of each team. In addition, the instructor assists the team in developing solutions to unresolved problems they encounter as they study. The last ten to fifteen minutes of class is used for a guided evaluation and feedback period. Each team reflects on what worked well and the challenges they encountered during their study time. The teams conclude each class by sharing an evaluation of their team's progress. The instructor/facilitator guides the discussion and offers feedback as needed. Each team also documents their progress on a form. A copy of the form is sent to the math or physics faculty.

At the next class meeting, the instructor reviews the particular skills that the teams practiced during the previous class meeting and answers questions. Depending on the level of knowledge of study skills the teams have at each point in time, the instructor also teaches mini-lessons about various active-learning study techniques. For example, a lesson on acronyms and mnemonics can be taught to assist the teams' learning a physics concept.

Phase Three begins around week five, when each team's maturity level and study skills have again increased. They have improved their ability to handle conflict. Consequently, each team transitions into the norming (effective use of conflict resolution) stage of group development. Each team has found its rhythm and uses more of the class meeting time to study math or physics. The instructor/facilitator offers instruction and support only when it is needed. At this point, some study teams may be autonomous (little need for guided instruction, team studies without major conflicts, team self evaluates).

Phase Four begins when the team has moved into the performing stage of group development. The team is now capable of meeting independently. Each team is responsible for completing a weekly progress report and sending it to the STSC instructor. They are expected to continue meeting for the rest of the semester. In addition, teams are responsible for contacting the STSC instructor if they are unable to resolve any conflicts on their own.

The STSC instructor teaches group dynamics, study team skills, and study skills. There is no expectation that the STSC instructor will teach math or physics. When students have difficulty with the math or physics subject matter, the STSC instructor helps the students use study-skill strategies to solve the problem. Examples include using Socratic dialogue to help the students 
teach each other the material and use of the text or class notes to find material that will help them solve problems. Students are given the responsibility of asking the faculty member teaching the math or physics course for help with technical problems the team cannot solve.

IV. Theoretical Framework of the STSC: Educational Philosophy and Models

For the program to be most effective, it was felt that the STSC should be based on studentcentered learning and constructivism. The educational philosophies and models used to design the STSC are included here for completeness.

John Dewey, an eighteenth-century philosopher, is often referred to as the father of American educational philosophy. His "educational creed" [11] is based on student-centered learning as opposed to the more traditional teacher-centered learning. Constructivist philosophy [12] is similar in many ways to Dewey's philosophy and is based on the idea that humans can only clearly understand what they themselves have constructed.

All of the activities, mini-lessons, subject-matter study time, and team evaluation were designed to be student-centered. Each student is expected to take an active role in learning and construct a set of team-building skills and study skills that they can use in many other settings, both in their academic and professional lives.

Two educational models, Bloom's Taxonomy and the Hersey-Blanchard Leadership Model, provide the framework for designing the progressively more complex student-centered learning over the six weeks of the STSC.

Benjamin Bloom's Education Taxonomy [13] helps teachers to design and assess curricula. It enables teachers to create specific and measurable learning objectives that give meaningful direction to the students' learning experience. Objectives may be written in one of three domains: cognitive, affective, and psychomotor. Teachers usually write objectives from the cognitive domain.

There are six progressively more complex levels of the taxonomy. They are: knowledge, comprehension, application, analysis, synthesis, and evaluation. Knowledge and use of these levels helps teachers to decide which active-learning methods, problem-solving processes, and critical-thinking strategies best encourage student learning for a specific objective, at a specific point in the student's progression through the levels of the taxonomy.

The Hersey-Blanchard Leadership Model [14] can help teachers understand the value of different styles of leadership in the classroom. The model is comprised of two parts. The first is a continuum and it measures the maturity level of the group. The immature group requires more direction and leadership than the mature group. The second key part of the model is situational leadership. Four leadership styles can be used; telling, selling, participating, and delegating. Depending on the objectives of the lesson and the skills and maturity level of the group, the leader can choo se which leadership style will be most effective. 
Bloom's taxonomy and the leadership model give teachers the framework to continuously evaluate the students' learning. Based on the evaluation, the teacher can facilitate students' learning at the proper level with the appropriate leadership style. The STSC was designed to have the flexibility to use both of these models. Mini-lessons are taught on an as-needed basis and can be taught using the appropriate level of complexity and leadership style. The timing of the phases of the course is flexible, so that each team can progress through the group development stages at different rates. The facilitator role of the STSC instructor, as opposed to teacher role, challenges the students to work at their maximum capability.

Student-centered educational principles, educational models, retention models, and the four stages of group development were combined to allow the instructor to optimally emphasize the active and reflective nature of learning for the STSC participants.

\section{Implementation and Results of the Fall 2002 STSC Pilot}

The STSC was implemented in the third week of the Fall 2002 semester. The days and times the course was offered were advertised to the students through posters, the campus TV channel, email, and the college newspaper. In addition, the Retention Coordinator offered a five-minute presentation to each introductory math and physics class and told the students about the benefits of the study team course and what other services she offered.

Several study teams of students were formed during this Fall 2002 pilot. The major successes were:

- The students who attended the STSC consistently saw an improvement on their test scores and their understanding of the material as reported by students in a follow-up questionnaire.

- Students actively learned the material, which increased their long-term memory of the material, as evidenced by the STSC instructor's weekly, recorded observations.

- Students' quiz grades improved after they started participating in the STSC (in the fourth week of the semester) as reported by the students.

- Math and physics faculty reported an improvement in the STSC students' class participation.

- Each team's group development skills and study skills improved, as evidenced by the recorded observations and evaluation checklist that the STSC instructor made at each class meeting.

The lessons learned during the Fall 2002 pilot include:

The class meeting times that were offered in the Fall 2002 semester conflicted with many of the interested students' schedules and as a result, some students were unable to participate. In order to accommodate more students in the Spring 2003 semester, the STSC was offered at custom times that worked around each student's schedule.

A longer presentation was needed to explain the benefits of taking the STSC and to avoid 
students' misconceptions about the purpose of the course. Perhaps the biggest misconception was that students thought that the STSC instructor would tutor them in math and physics and they could "drop-in" whenever they needed help.

One final challenge was the students' commitment and attendance. Sporadic attendance was a problem for a few of the teams. Since an efficiently functioning team depends on consistent attendance from each team member, it was essential to obtain an attendance commitment from every student taking the seminar from the onset. The Retention Coordinator made a note of this challenge and emphasized this point in her presentations for the Spring 2003 semester.

\section{Spring 2003 STSC Implementation and Results}

Based on the lessons learned in the Fall 2002 semester, the following changes were made before the STSC was implemented in the Spring 2003 semester:

A presentation was made at school faculty meetings at the end of the Fall 2002 semester to solicit faculty who would be interested in supplementing their courses with the STSC.

Fifteen faculty members expressed an interest in participating in the program for Spring 2003. The Retention Coordinator met with each faculty member twice towards the end of the Fall 2002 semester to determine the best way to implement the expanded program. A few key decisions that were discussed were when the presentations would be made and if the faculty member was going to offer an incentive to the students for participation in the STSC.

Faculty members promoted and explained their reasons for encouraging student participation in the STSC before the Retention Coordinator made her 20-minute presentation. Some faculty offered incentives, such as extra points awarded towards quiz or homework grades for each STSC class a student attended.

An expanded twenty-minute presentation was made to the students in the first week of the Spring 2003 semester. It included: FAQ's about the STSC, a brief explanation about benefits of the STSC and how it would improve their knowledge and grades, the structure and format of the program, the commitment involved, a question and answer period, and a sign-up form. The signup form emphasized the necessary, student's commitment to the program and their responsibilities for participation.

Customized class times were offered. The sign-up form asked students to fill out their schedule, so the STSC instructor could coordinate class times based on the students' schedules.

Results for the Spring 2003 STSC include:

Over one hundred and twenty-five students signed up for the Spring 2003 session, which is four times the number of students who participated in the Fall 2002 pilot.

The students who signed up for the course had a better understanding of the benefits of the 
STSC, the required attendance commitment, and their instructor's commitment to the program.

Subject matter faculty in physics reported that students in the study teams were actively working as a team before each physics class began (comparing answers they had gotten on homework problems, teaching each other how to do homework problems). This teamwork continued during active-learning activities during class and during physics labs.

Subject matter faculty in physics reported that the students on the study teams were friendly towards each other in class and lab and their attitude about studying physics was improved with this additional social aspect.

Improved grades, observed active learning, increased class participation, and improved group development skills and study skills, as reported in the Fall 2002 semester, continued in the Spring 2003 STSC.

VII. Future Improvements

- The STSC could be offered for more introductory courses in other majors. Depending on the number of classes and the number of students served, there would be staffing and space considerations.

- A faculty-training seminar would actively engage faculty in the program as promoters and advisors.

- More quantitative data is being collected during the Spring 2003 offering and student retention rates for the STSC participants will be evaluated in the Fall of 2003.

- The STSC could be integrating into a formal retention program at SUNY Morrisville that would unify the college's other retention efforts. (An integration of all of the retention programs at SUNY Morrisville would presumably result in the benefits experienced by other retention programs described in this paper.)

- Making the STSC a formal course offering that the students could register for would make the course more accessible to students, since they would have a scheduled block of time for the STSC, and it would add an incentive for the students, since it would now be on their transcript.

- Including a pass/no pass grade based solely on attendance would avoid a team's failure due to sporadic attendance.

VII. Conclusions

Studies have shown that there is overwhelming evidence that overall student success is largely determined by students' experiences during the freshman year [15]. Students participating in the STSC made personal connections with students, faculty, and staff, they improved their academic success, and developed life-long team building and study skills. These results are important indicators that the STSC was successful in fostering measurable student engagement and has been a worthwhile program at SUNY Morrisville. 


\section{Acknowledgement}

The Retention Coordinator position was made possible, for one year, through a grant from New York State and the federal Carl D. Perkins VATEA grant.

\section{References}

[1] Seidman, A. Retention Revisited: R=E, Id+E \& In, Iv. College and University v71. n4. p18-20. Spr. 1996.

[2] Braxton, J. M. (ed.). Reworking the Student Departure Puzzle. $1^{\text {st }}$ ed. Vanderbuilt University Press. 2000.

[3] http://www.iub.edu/ nsse/html/deep/framework.htm. Copyright C1999-2002 National Survey for Student Engagement.

[4] Tinto, V. Leaving College: Rethinking the causes and cures of student attrition. Chicago: The University of Chicago Press. 1993.

[5] Upcraft, M.L., Gardner, J. N., and Associates. The Freshman Year Experience: Helping students survive and succeed in college. San Francisco: Jossey-Bass Inc, Publishers. 1989.

[6] Meserol, P., "Holding On". Syracuse. Summer 2002. Vol. 19. No. 2. p. 26.

[7] The University Learning Center. $<$ http://www.uncc.edu/ univlern $>1 / 8 / 03$.

[8] http://www.hawkeyebasketball.com/about/retention.htm 2000@ University of Iowa Men's Intercollegiate Athletics

[9] Argyris, C.and Schön, D. A. Organizational learning II: theory, method and practice. Reading, Mass. Addison-Wesley, 1996

[10] Hubbard, K. A. and Katz, D. M., The Physics Toolbox: A Survival Guide for Introductory Physics. p. 40. Ontario Canada: Thomson Learning, Inc. 2002.

[11] Archambault, R.D. John Dewey on Education: Selected writings. New York: Random House, Inc. 1964.

[12] Brooks, Jacqueline Grennon, and Martin G. Brooks. In Search of Understanding: The Case for Constructivist Classrooms. Alexandria, VA: Association for Supervision and Curriculum Development, 1993.

[13] Bloom, B. (ed). Taxonomy of Educational Objectives. New York: David McKay Company, Inc. 1956.

[14] Hersey, P. and Blanchard, K.H., Management of Organizational Behavior: Utilizing Human Resources (3r ed.), p. 170. Englewood Cliffs, NJ: Prentice-Hall, Inc. 1977.

Joan V. Dannenhoffer, P.E., is Assistant Professor of Physics at SUNY Morrisville. She received a B.S. in Civil Engineering and an M.B.A. from Rensselaer Polytechnic Institute and a M.S. in Environmental Engineering from the University of Connecticut. Her research interests include mathematical modeling of environmental engineering problems and educational psychology.

Nicole L. Loock, is a Student Retention Coordinator at SUNY Morrisville. She received a B.A. in English and Secondary Education from SUNY Potsdam and an M.S.E. from SUNY Cortland. She taught high school English for 5 years in a juvenile detention center. Her research interests include retention, higher education models, learning styles, active-learning theories, alternative education, outdoor and adventure education.

Proceedings of the 2003 American Society for Engineering Education Annual Conference \& Exposition Copyright (C) 2003, American Society for Engineering Education" 